\title{
A simulated client exploration of nonprescription availability of antibiotics at drugstores for childhood acute diarrhea and upper respiratory infection in Lahore, Pakistan
}

\author{
Usman Rashid Malik \\ Xi'an Jiaotong University \\ Jie Chang \\ Xi'an Jiaotong University \\ Furqan Hashmi \\ University of the Punjab \\ Naveel Atif \\ Xi'an Jiaotong University \\ Hareem Basir \\ Royal Albert Edward Infirmary \\ Khezar Hayat \\ Xian Jiaotong University \\ Faiz Ullah Khan \\ Xi'an Jiaotong University \\ John Alimamy Kabba \\ Xi'an Jiaotong University \\ Krizzia Lambojon \\ Xi'an Jiaotong University \\ Yu Fang ( $\nabla$ yufang@mail.xjtu.edu.cn ) \\ Xi'an Jiaotong University
}

Research

Keywords: Antibiotics, Non-prescription, Drugstores, Community pharmacies, Simulated Client, Pakistan

Posted Date: November 10th, 2020

DOl: https://doi.org/10.21203/rs.3.rs-103467/v1

License: (c) (i) This work is licensed under a Creative Commons Attribution 4.0 International License.

Read Full License 
Page $2 / 19$ 


\section{Abstract}

Background The excessive consumption of antibiotics is a major contributor to antimicrobial resistance, especially in children. Children are often being advised antibiotics for viral infections. In developing countries, the drugstores are a prime source of easy access to nonprescription antibiotics. Also, in Pakistan, their irrational use is an "everyday routine". The study, therefore, aimed to evaluate the dispensing of nonprescription antibiotics for children at drugstores of Lahore, Pakistan.

Methods Using the pediatric acute diarrhea and acute upper respiratory infection as disease scenarios, a simulated client, cross-sectional study was conducted in Lahore, Pakistan to explore the antibiotics' ease of availability at both categories of drugstores (pharmacies and medical stores) from November $1^{\text {st }}, 2019$ to January $31^{\text {st }}, 2020$. Chi-square $\left(x^{2}\right)$ test was used to compare the differences in practices of different categorical variables. Multivariable logistic regression was applied to analyze the association of various factors with antibiotics dispensing.

Results Antibiotics were dispensed without prescription in 456 (59\%) of 773 simulated visits out of which $425(93.2 \%)$ were dispensed on the advice of the drugstore staff. The qualified pharmacist was available in only $164(21.2 \%)$ cases. Of 386 visits for acute diarrhea and 387 for acute upper respiratory infection, nonprescription antibiotic dispensing occurred in 259 (67.1\%) and 197 (50.9\%) visits respectively. The considerable differences ( $p$-value $<0.05)$ were observed between the practices of the towns, disease scenario presented, categories of drugstores, and pharmacist-supervised drugstores.

Conclusions The inappropriate dispensing practices were prevalent to a large extent at the drugstores and antibiotics were effortlessly obtainable without prescriptions. The quality of the services provided, especially by the non-pharmacist staff, was also not satisfactory. Therefore, the Drug Regulating Authority of Pakistan must enforce strict implementation of drug laws at the drugstores without delays especially in major cities to help curb the felonious use of antibiotics.

\section{Background}

The decline in the discovery of new antibiotic molecules and a corresponding increase in antimicrobial resistance (AMR) levels is conceding the management of infectious diseases and is posing a significant threat to human lives globally [1]. AMR has become an issue of international priority in the last two decades, and the World Health Organization (WHO) in their meeting of Global Action Plan (2015) on AMR clearly stated that the prudent use of antibiotics has become a need of the hour to control AMR [2]. The inappropriate use of antibiotics increases hospital stays, high costs, increased adverse effects, treatment failures, and the development of resistance to antibiotics [3],[4]. The excessive and irrational consumption of antibiotics is noticed more often in developing countries than in the developed world [5].

WHO's Antibiotic Consumption Surveillance Report (2016-2018) stated that the use of antibiotics appears to be significantly high in certain parts of the world [6]. Several factors, including economic growth and access to antibiotics, have driven this global growth in consumption [7]. Retail outlets 
represent one of the most vital antimicrobial sources worldwide [8]. Various simulated client (SC) studies conducted worldwide to evaluate nonprescription availability of antibiotics at drugstores had reported their widespread irrational use for nonbacterial infections [8-13]. According to the WHO's latest multicountry public awareness survey, 93 percent of people had their most recent antimicrobial taken from a pharmacy and drugstore [1]. Such antibiotics are either recommended by a healthcare provider or obtained from a number of pharmacy outlets without a formal prescription. Antibiotics sale without a prescription is prohibited in many countries, yet, the community pharmacies/drugstores are a major source of non-prescribed antibiotics [14]. Often, in developing countries there is either a complete absence of regulations for selling of antibiotics or, otherwise, the laws exist but there is a lack of enforcement of these regulations [15]. Apart from the lack of governance in the health sector, behavioral and socioeconomic conditions of customers are important factors that cause the non-prescription use of antibiotics [16].

Children, particularly infants, are vulnerable to bacterial infections. Across Asia, one child dies every two minutes because of infections instigated by resistant bacteria [17]. Statistics from low-income and middle-income countries show that, due to the emergence of resistance to first-line antibiotics, $70 \%$ of hospital-acquired neonatal infections may not be treated effectively using the WHO-approved regimen [18]. Antibiotics are the most widely prescribed drugs for children in hospitals and the community [19]. Children suffer from viral infections more often than adults [20]. Antibiotics are often recommended to such children who have viral or non-infectious illnesses. In some cases, children who suffer from infections for which narrow-spectrum drugs are suggested and recommended are frequently advised wide spectrum antibiotics [21].

In Pakistan, the under-five mortality rate in 2018 was 69/1000 children which was the highest in South Asia [22]. Being a country of lower-middle-income status, antibiotics selling at community pharmacies without prescription is a problem of high concern in Pakistan. The current legislation in Pakistan prohibits the sale of antibiotics at all drugstores without a valid prescription from a registered medical doctor [23]. Still, the evidence indicates that retail outlets have a common practice of dispensing antibiotics irrationally for acute infections due to lack of knowledge and/or commercial or business interests [24]. Also, a wide disparity exists in terms of education, knowledge and quality of services provided at the drugstores in Pakistan [25],[26]. Various studies conducted to evaluate the self-medication with antibiotics have revealed the high prevalence rates of antibiotics' self-use especially for gastrointestinal and respiratory problems [5],[27]. Health professionals especially pharmacists and other pharmacy staff have a prime duty to mitigate the misuse of antibiotics at community levels [28]. In the last few years, no study has been conducted in Pakistan to evaluate dispensing practices for children at the drugstores. Therefore, studies are needed to evaluate the extent of antibiotics nonprescription use at drugstores particularly for children who are at high risk of developing AMR.

\section{Methods}

\section{Study Setting}


Lahore, a metropolitan city and the capital of Punjab Province in Pakistan was chosen as a target city for our study. The city spans over 1772 square kilometers, accommodates approximately 12.6 million people and has the most advanced setup of drug-outlets in the province. Lahore is geographically divided into ten administrative towns and is comprised of urban and suburban populations. These towns are Aziz Bhatti Town, Data Ganj Baksh Town, Gulberg Town, Allama Iqbal Town, Lahore Cantonment Area, Nishtar Town, Samanabad Town, Shalimar Town, Ravi Town and Wahga Town [29].

\section{Study Design}

A cross-sectional survey was conducted on drugstores of Lahore, Pakistan from November 1st, 2019 to January 31 st, 2020 by using the simulated client method to evaluate overall practices at drug outlets regarding over-the-counter (OTC) sale of antibiotics. There are two categories of drugstores in Pakistan, namely, pharmacy and medical store. Pharmacies require the license of a pharmacist and medical stores require assistant pharmacist licensure. Both categories of drugstores can dispense an antibiotic with a legal prescription. Therefore, both categories located in all towns were included in the study. An updated list of registered pharmacies and medical stores of Lahore city was obtained from the Primary and Secondary Healthcare Department of Punjab Province and the final sample list was generated from that full list of registered pharmacies and medical stores in Lahore.

\section{Sampling and Sample Size}

There are 3947 registered drug outlets in all ten towns of Lahore city, excluding the distributors and wholesalers. A proportionate stratified random sampling procedure was used for the selection of drug outlets based on the geographical towns. At first, a separate list of the drugstores was generated for all ten administrative towns, and then from each list of individual towns, a sample list was generated through random selection by using the 'rand()' function in Microsoft Excel. At a minimum, $8 \%$ of drugstores (including both pharmacies and medical stores) from each town were selected to make the best representative sample.

The sample size for the study was calculated by Raosoft Sample Size Calculator by assuming a 50\% prevalence of non-prescription use of antibiotics, $5 \%$ margin of error, and $95 \%$ confidence interval (Cl) [30]. The final sample size obtained was 351 drug outlets, however, keeping in view the difficulties for simulated clients in searching the locations of drugstores and also the possibility of shut-down of a few of the stores, a total of 400 drugstores were chosen out of 3947 outlets.

\section{Simulated Scenarios}

The pediatric acute diarrhea and acute upper respiratory tract infection (URTI) were chosen as fictional disease scenarios to visit the selected drugstores. Acute diarrhea and acute URTI are mostly non-bacterial infections. In children, acute diarrhea is typically caused by rotaviruses and sometimes due to food poisoning or bacteria. The typical symptoms are loose stools (no blood in stool) with tiredness or weakness. Acute URTI, in children, also is of viral origin in most instances and the typical symptoms may include a runny nose, nasal congestion, sneezing, and cough with or without fever. The management of these acute diseases in most of the cases should be symptomatic and the use of antibiotics in such 
cases does not have added advantage. In our study, we developed standard protocols for each disease scenario [Additional File 1] and provided adequate training to the simulated clients who acted as the relative of a 3-5 years old child having a problem of acute diarrhea or acute URTI.

\section{Data Collection Procedure}

A pre-designed data record form was adopted from a previous study conducted to evaluate antibiotics sales at community pharmacies [9]. The form was modified according to local settings. Eight undergraduate pharmacy students having adequate medical background were engaged as simulated clients (SCs) and were adequately trained about the visit process and the disease scenarios under the supervision of a registered medical specialist and experts in the field of pharmacy practice. Each SC strictly followed the predesigned standardized procedure and presented the same scenario in all visits.

The clients first visited the drugstore, observed some basic parameters about the store and the staff, and then presented the disease scenario. After completion of the visit, they filled the data record form containing the information about baseline characteristics, antibiotics dispensed, and patient counseling. Two levels of demand were presented by the SCs to get the medication for the assumed disease condition. At the first level of demand, the client told the pharmacy attendant about the symptoms of the disease and demanded a suitable medication. In case, the staff didn't dispense antibiotic at the first level, the client then directly demanded from the staff to dispense any antibiotic in the second level of demand. The simulated clients did not buy any medicines and instead presented a suitable reason to avoid the purchase of medicines before leaving the drugstore. The clients presented an acute diarrhea scenario at 386 drug-stores and an acute URTI at 387 outlets. The outlets which were closed during the client visit and those which were untraceable were excluded from the study.

To ensure the quality of the survey and consistency of the data collected, the clients rehearsed the visit process and the scenarios many times to make sure they don't mislay the recommended guidelines. Furthermore, they visited a few drugstores to achieve fluency in their presentation and to get acclimatized to the actual situations before starting the main study.

\section{Statistical Analysis}

The data were first entered and then analyzed using the IBM-SPSS version 22.0. The percentage of antibiotics dispensed without prescription was the main outcome of the study. The descriptive statistics were applied to calculate frequencies and percentages. A Chi-square test was used to (i) compare the differences in dispensing practices between both disease scenarios, (ii) pharmacy practices with and without the supervision of qualified pharmacists and (iii) dispensing practices at both categories of drugstores. Multivariate logistic regression was also applied to evaluate the association of different factors to the non-prescription dispensing of antibiotics.

\section{Results}

\section{Overall Dispensing Practices}


Overall, 773 visits were made at the selected drugstores in all ten administrative towns. From 773 visits, only in 28 (3.6\%) cases, the attending staff was a female. The antibiotics were dispensed in 456 (59\%) cases, mostly (93.2\%) were provided at the first demand level without mentioning the need for an antibiotic. The licensed pharmacist was present on duty in only 164 (21.2\%) visits. In 643 (83.2\%) visits, the staff did not even bother to request a prescription from the SCs and provided counseling about the dispensed drugs in only 307 (39.7\%) cases. (Table 1) The multivariable logistic regression data showed significantly high proportion of non-prescription dispensing of antibiotics in seven administrative towns of the city. (Table 2)

Table 1

Characteristics and Practices of Visited Drugstores (Total Simulated Visits N=773)

\begin{tabular}{|c|c|}
\hline Characteristics & Frequency (\%) \\
\hline \multicolumn{2}{|l|}{ Licensed Pharmacist on Duty } \\
\hline Yes & $164(21.2)$ \\
\hline No & $609(78.8)$ \\
\hline \multicolumn{2}{|l|}{ Gender of Attending Staff } \\
\hline Male & $745(96.4)$ \\
\hline Female & $28(3.6)$ \\
\hline \multicolumn{2}{|l|}{ Age of attending staff } \\
\hline Less than 30 years & $301(38.9)$ \\
\hline $30-50$ years & $433(56.0)$ \\
\hline More than 50 years & $39(5.1)$ \\
\hline \multicolumn{2}{|l|}{ Further Inquired About Patient Condition } \\
\hline$\overline{Y e s}$ & $456(59.0)$ \\
\hline No & $317(41.0)$ \\
\hline \multicolumn{2}{|l|}{ Dispensed Antibiotic without Prescription } \\
\hline Yes & $456(59.0)$ \\
\hline No & $317(41.0)$ \\
\hline \multicolumn{2}{|c|}{ Prime Reason provided for Not Dispensing Antibiotic $(\mathrm{N}=317)$} \\
\hline Must be dispensed with prescription & $143(45.1)$ \\
\hline No need to use antibiotics & $124(39.1)$ \\
\hline Indications not clear and needs a referral & $50(15.8)$ \\
\hline \multicolumn{2}{|c|}{ Under which demand level Antibiotic is dispensed $(\mathrm{N}=456)$} \\
\hline Demand Level 1 & $425(93.2)$ \\
\hline Demand Level 2 & $31(6.8)$ \\
\hline \multicolumn{2}{|l|}{ Did the Staff requested a prescription } \\
\hline Yes & $130(16.8)$ \\
\hline No & $643(83.2)$ \\
\hline \multicolumn{2}{|l|}{ Recommended a referral to physician } \\
\hline Yes & $156(20.2)$ \\
\hline No & $617(79.8)$ \\
\hline \multicolumn{2}{|c|}{ Provided counseling or advice about drugs dispensed } \\
\hline Yes & $307(39.7)$ \\
\hline No & $466(60.3)$ \\
\hline
\end{tabular}

Table 2

Factors associated with dispensing of antibiotics without prescription 


\begin{tabular}{|c|c|c|c|c|c|c|}
\hline \multirow[t]{3}{*}{ Characteristics } & \multirow{3}{*}{$\begin{array}{c}\text { Total } \\
(\mathrm{N}=773) \\
\mathrm{N}(\%)\end{array}$} & \multicolumn{2}{|c|}{ Dispensed Antibiotic } & \multicolumn{3}{|c|}{ Multiple Logistic Regression } \\
\hline & & Yes $(\mathrm{N}=456)$ & No $(\mathrm{N}=317)$ & \multirow[t]{2}{*}{ p-value } & \multirow[t]{2}{*}{ OR } & \multirow[t]{2}{*}{$95 \% \mathrm{CI}$} \\
\hline & & n (\%) & n (\%) & & & \\
\hline \multicolumn{7}{|l|}{ Age of staff } \\
\hline Less than 30 years & $301(38.9)$ & $166(55.1)$ & $135(44.9)$ & & Ref & \\
\hline $30-50$ years & $433(56)$ & $262(60.5)$ & $171(39.5)$ & 0.160 & 1.266 & $0.911-1.760$ \\
\hline More than 50 years & $39(5.1)$ & $28(71.8)$ & $11(28.2)$ & 0.190 & 1.695 & $0.770-3.728$ \\
\hline \multicolumn{7}{|l|}{ Gender of staff } \\
\hline Male & $745(96.4)$ & $445(59.7)$ & $300(40.3)$ & & Ref & \\
\hline Female & $28(3.6)$ & $11(39.3)$ & $17(60.7)$ & 0.774 & 0.881 & $0.371-2.092$ \\
\hline \multicolumn{7}{|c|}{ Licensed Pharmacist on Duty } \\
\hline Yes & $164(21.2)$ & $78(47.6)$ & $86(52.4)$ & & Ref & \\
\hline No & $609(78.8)$ & $378(62.1)$ & $231(37.9)$ & 0.367 & 1.263 & $0.761-2.096$ \\
\hline \multicolumn{7}{|l|}{ Drugstore Size } \\
\hline Larger & $80(10.4)$ & $39(48.8)$ & $41(51.2)$ & & Ref & \\
\hline Medium & $495(64)$ & $305(61.6)$ & $190(38.4)$ & 0.844 & 1.059 & $0.600-1.868$ \\
\hline Small & $198(25.6)$ & $112(56.6)$ & $86(43.4)$ & 0.406 & 0.762 & $0.402-1.446$ \\
\hline \multicolumn{7}{|l|}{ Drugstore category } \\
\hline Pharmacy & $326(42.2)$ & $171(52.5)$ & $155(47.5)$ & & Ref & \\
\hline Medical Store & $447(57.8)$ & $285(63.8)$ & $162(36.2)$ & 0.071 & 1.452 & $0.969-2.176$ \\
\hline \multicolumn{7}{|l|}{ Drugstore Type } \\
\hline Independent & $720(93.1)$ & $428(59.4)$ & $292(40.6)$ & & Ref & \\
\hline Chain & $53(6.9)$ & $28(52.8)$ & $25(47.2)$ & 0.848 & 0.935 & $0.471-1.857$ \\
\hline \multicolumn{7}{|c|}{ Disease scenario presented } \\
\hline Pediatric acute diarrhea & $386(49.9)$ & $259(67.1)$ & $127(32.9)$ & & Ref & \\
\hline Pediatric acute URTI & $387(50.1)$ & $197(50.9)$ & $190(49.1)$ & $<0.001^{*}$ & 0.468 & $0.344-0.636$ \\
\hline \multicolumn{7}{|l|}{ Administrative Towns } \\
\hline Cantonment Area & $74(9.6)$ & $29(39.2)$ & $45(60.8)$ & & Ref & \\
\hline Nishtar Town & $100(12.9)$ & $72(72.0)$ & $28(28.0)$ & $<0.001^{*}$ & 3.397 & $1.718-6.718$ \\
\hline Shalimar Town & $70(9.1)$ & $37(52.9)$ & $33(47.1)$ & 0.208 & 1.580 & $0.775-3.220$ \\
\hline Wahga Town & $45(5.8)$ & $24(53.3)$ & $21(46.7)$ & 0.185 & 1.695 & $0.777-3.695$ \\
\hline Ravi Town & $67(8.7)$ & $42(62.7)$ & $25(37.3)$ & $0.019 *$ & 2.342 & $1.153-4.758$ \\
\hline Samanabad Town & $76(9.8)$ & $54(71.1)$ & $22(28.9)$ & $<0.001^{*}$ & 4.213 & $1.998-8.880$ \\
\hline Gulberg Town & $44(5.7)$ & $35(79.5)$ & $9(20.5)$ & $<0.001 *$ & 6.457 & $2.577-16.178$ \\
\hline Allama Iqbal Town & $175(22.6)$ & $103(58.9)$ & $72(41.1)$ & $0.005^{*}$ & 2.274 & $1.274-4.058$ \\
\hline Data Ganj Baksh Town & $76(9.8)$ & $32(42.1)$ & $44(57.9)$ & 0.847 & 1.070 & $0.539-2.125$ \\
\hline Aziz Bhatti Town & $46(6.0)$ & $28(60.9)$ & $18(39.1)$ & $0.048 *$ & 2.239 & $1.009-4.971$ \\
\hline
\end{tabular}

$\mathrm{OR}=$ Odds ratio, $\mathrm{CI}=$ Confidence interval

Of the 456 simulated visits in which an antibiotic was provided to the SCs for either childhood diarrhea or URTI, 261 (57.2\%) inquired further about the disease/patient condition, and 148 (32.5\%) asked whether the patient had previously taken any drug or treatment. However, only 20 (4.4\%) questioned about the patient's history of drug allergy. The counseling about antibiotics usage was provided in 231/456 (50.7\%) cases. Interestingly, in $6 / 456(1.3 \%)$ cases, the staff requested a prescription from the SCs and still dispensed the antibiotics and in 13/456 (2.9\%) cases, the staff after providing an antibiotic for the disease condition recommended the customer to visit a physician for further advice. (Figure 1)

The most frequently dispensed antibiotics for pediatric acute diarrhea were metronidazole 171 (54.6\%), cefixime 88 (28.1\%), and ciprofloxacin 48 (15.3\%). Other less frequent antibiotics were amoxicillin, 
erythromycin, and clarithromycin. For acute URTI, cefixime was the commonly recommended and dispensed antibiotic, 102 (49.8\%), followed by Co-Amoxiclav 32 (15.6\%), ciprofloxacin 14 (6.8\%), erythromycin 14 (6.8\%), amoxicillin $13(6.3 \%)$ and azithromycin 10 (4.9\%). Some other antibiotics like clarithromycin, levofloxacin, cefuroxime, cefadroxil, and co-trimoxazole were also provided to SC in fewer cases. (Figure 2) The most frequent non-antibiotic medicines dispensed for diarrhea management were oral rehydration salts (ORS), bismuth subsalicylate syrups, and zinc syrup. Nasal decongestant syrups, allergy syrups, and cough syrups were the most common non-antibiotic medicines dispensed for URTI.

\section{Dispensing Practices for Acute Diarrhea and Acute Upper Respiratory Infection}

Out of 386 drugstores visited for acute diarrhea, the antibiotics were dispensed in 259 (67.1\%) cases out of which $236(91.1 \%)$ were given to the customers without even asking for an antibiotic (Demand Level 1). Surprisingly, in $55 / 259$ (21.2\%) visits where the antibiotic was dispensed, two antibiotics were handed over to the SCs at a time. Only in 62/386 (16.1\%) cases, the staff asked for a prescription from the clients when they requested for an antibiotic and in 71/386 (18.4\%) visits, the staff recommended the clients to visit a physician for better advice. For acute URTI, the antibiotics were easily available to the clients without a prescription in 197 (50.9\%) (Approximately half) visits, and 189/197 (95.9\%) were dispensed at the first level of demand. In 7/197 (3.6\%) situations, two antibiotics were given to the clients at a time. Prescriptions were not requested from the SCs in 319/387 (82.4\%) visits. The results indicated significant differences ( $p$-value $<0.05$ ) between the disease scenarios in terms of the proportions of antibiotics dispensed, the number of antibiotics dispensed at a single simulated visit, and in the counseling services provided to SCs with p-values $<0.001,<0.001$ and 0.003 respectively. (Table 3 ) The multivariate logistic regression also showed a significant association between the dispensing of non-prescription antibiotics and the disease scenarios presented with an odds ratio (OR) $0.468(95 \% \mathrm{Cl} 0.344-0.636)$ and $\mathrm{p}<0.001$, for acute URTI. (Table 2)

\section{Dispensing Practices of Pharmacist and Non-Pharmacist Supervised Drugstores}

There was a significant difference in the majority of practices and services provided at the drugstores (better at drugstores supervised by pharmacists than unsupervised ones). A statistically significant difference was seen in the frequency of antibiotics dispensed ( $p=0.001)$, inquiries about patients' condition ( $p<0.001)$, request of a prescription from the SCs $(p<0.001)$, referral to the physician $(p<0.001)$ and the counselling about medications $(p=0.001)$. The availability of qualified pharmacists at drug outlets was limited to only $164(21.2 \%)$ visits. The drugstores with pharmacist dispensed antibiotics in $78 / 164(47.6 \%)$ cases whereas those without a qualified pharmacist dispensed in $378 / 604(62.1 \%)$ cases. Inquiries about patients' disease status were asked in $84.1 \%$ cases in pharmacist-supervised stores which is quite high compared to $52.2 \%$ at unsupervised stores. Also, the counseling about the dispensed medications was provided more often (51.2\%) in comparison to non-pharmacist supervised stores (36.6\%). (Table 4)

\section{Table 3:}


Differences in practices of drugstores for each disease scenario presented

\begin{tabular}{|c|c|c|c|}
\hline \multirow[t]{3}{*}{ Characteristics } & \multicolumn{2}{|c|}{ Disease Scenario Presented } & \multirow[t]{3}{*}{ p-value } \\
\hline & Pediatric Diarrhea $(\mathrm{N}=386)$ & Pediatric URTI ( $\mathrm{N}=387)$ & \\
\hline & Frequency (\%) & Frequency (\%) & \\
\hline \multicolumn{3}{|c|}{ Further Inquired About Patient Condition } & 0.793 \\
\hline Yes & $230(59.6)$ & $226(58.4)$ & \\
\hline No & $156(40.4)$ & $161(41.6)$ & \\
\hline \multicolumn{3}{|c|}{ Dispensed Antibiotic without Prescription } & $<0.001$ \\
\hline Yes & $259(67.1)$ & $197(50.9)$ & \\
\hline No & $127(32.9)$ & $190(49.1)$ & \\
\hline \multicolumn{3}{|c|}{ Number of antibiotics dispensed in simulated visits } & $<0.001$ \\
\hline One & $204(78.8)$ & $190(96.4)$ & \\
\hline Two & $55(21.2)$ & $7(3.6)$ & \\
\hline \multicolumn{3}{|c|}{ Under which demand level Antibiotic is dispensed } & 0.066 \\
\hline Demand Level 1 & $236(91.1)$ & $189(95.9)$ & \\
\hline Demand Level 2 & $23(8.9)$ & $8(4.1)$ & \\
\hline \multicolumn{3}{|c|}{ Did the Staff requested a prescription } & 0.642 \\
\hline Yes & $62(16.1)$ & $68(17.6)$ & \\
\hline No & $324(83.9)$ & $319(82.4)$ & \\
\hline \multicolumn{3}{|c|}{ Recommended a referral to physician } & 0.251 \\
\hline Yes & $71(18.4)$ & $85(22.0)$ & \\
\hline No & $315(81.6)$ & $302(78.0)$ & \\
\hline \multicolumn{3}{|c|}{ Provided counseling or advice about drugs dispensed } & 0.003 \\
\hline Yes & $174(45.1)$ & $133(34.4)$ & \\
\hline No & $212(54.9)$ & $254(65.6)$ & \\
\hline
\end{tabular}

Table 4:

Differences in practices between the drugstores supervised by pharmacist and without pharmacist 


\begin{tabular}{|c|c|c|c|}
\hline \multirow[t]{3}{*}{ Characteristics } & \multicolumn{2}{|c|}{ Licensed Pharmacist on Duty } & \multirow[t]{3}{*}{ p-value } \\
\hline & $\begin{array}{c}\text { Yes } \\
\text { (N=164 visits) }\end{array}$ & $\begin{array}{c}\text { No } \\
(\mathrm{N}=609 \text { visits })\end{array}$ & \\
\hline & n (\%) & n (\%) & \\
\hline \multicolumn{3}{|c|}{ Further Inquired About Patient Condition } & $<0.001$ \\
\hline Yes & $138(84.1)$ & $318(52.2)$ & \\
\hline No & $26(15.9)$ & $291(47.8)$ & \\
\hline \multicolumn{3}{|c|}{ Dispensed Antibiotic without Prescription } & 0.001 \\
\hline Yes & $78(47.6)$ & $378(62.1)$ & \\
\hline No & $86(52.4)$ & $231(37.9)$ & \\
\hline \multicolumn{3}{|c|}{ Under which demand level Antibiotic is dispensed } & 0.278 \\
\hline Demand Level 1 & $70(89.7)$ & $355(93.9)$ & \\
\hline Demand Level 2 & $8(10.3)$ & $23(6.1)$ & \\
\hline \multicolumn{3}{|c|}{ Did the staff asked whether had taken other drugs } & $<0.001$ \\
\hline$\overline{\text { Yes }}$ & $79(48.2)$ & $152(25)$ & \\
\hline No & $85(51.8)$ & $457(75)$ & \\
\hline \multicolumn{3}{|c|}{ Did the staff asked whether had any other symptoms } & 0.007 \\
\hline Yes & $71(43.3)$ & $193(31.7)$ & \\
\hline No & $93(56.7)$ & $416(68.3)$ & \\
\hline \multicolumn{3}{|c|}{ Did the staff asked regarding patient's drug allergy history } & 0.06 \\
\hline Yes & $11(6.7)$ & $19(3.1)$ & \\
\hline No & $153(93.3)$ & $580(96.9)$ & \\
\hline \multicolumn{3}{|c|}{ Did the Staff requested a prescription } & $<0.001$ \\
\hline Yes & $51(31.1)$ & $79(13.0)$ & \\
\hline No & $113(68.9)$ & $530(87.0)$ & \\
\hline \multicolumn{3}{|c|}{ Recommended a referral to physician } & $<0.001$ \\
\hline Yes & $65(39.6)$ & $91(14.9)$ & \\
\hline No & $99(60.4)$ & $518(85.1)$ & \\
\hline \multicolumn{3}{|c|}{ Provided counseling or advice about drugs dispensed } & 0.001 \\
\hline$\overline{\text { Yes }}$ & $84(51.2)$ & $223(36.6)$ & \\
\hline No & $80(48.8)$ & $386(63.4)$ & \\
\hline
\end{tabular}

\section{Dispensing Practices at Different Categories of Drugstores}

A significant difference was observed in the staff characteristics and their behaviors at different categories of drugstores (pharmacies and medical stores). Antibiotics were significantly more conveniently available from the medical stores than pharmacies $(p=0.002)$. The proportion of female staff was significantly higher $(p<0.001)$ at pharmacies compared to medical stores where the female staff was only found to be working in $3(0.7 \%$ cases). The differences were also seen in other practices such as inquiry about patient condition, requesting a prescription from the customer and referral to a physician $(p<0.05)($ Table 5$)$

\section{Table 5:}

Differences in characteristics and practices of different categories of drugstores 


\begin{tabular}{|c|c|c|c|}
\hline \multirow[t]{3}{*}{ Characteristics } & \multicolumn{2}{|c|}{ Drugstore Category } & \multirow[t]{3}{*}{ p-value } \\
\hline & $\begin{array}{c}\text { Pharmacy } \\
\text { (N=326 visits) }\end{array}$ & $\begin{array}{l}\text { Medical Store } \\
\text { ( } \mathrm{N}=447 \text { visits) }\end{array}$ & \\
\hline & $\mathrm{n}(\%)$ & n (\%) & \\
\hline \multicolumn{3}{|c|}{ Gender of Attending Staff } & $<0.001$ \\
\hline Male & $301(92.3)$ & $444(99.3)$ & \\
\hline Female & $25(7.7)$ & $3(0.7)$ & \\
\hline \multicolumn{3}{|l|}{ Age of attending staff } & $<0.001$ \\
\hline Less than 30 years & $170(52.1)$ & $131(29.3)$ & \\
\hline $30-50$ years & $146(44.8)$ & $287(64.2)$ & \\
\hline More than 50 years & $10(3.1)$ & $29(6.5)$ & \\
\hline \multicolumn{3}{|c|}{ Further Inquired About Patient Condition } & $<0.001$ \\
\hline Yes & $230(70.6)$ & $226(50.6)$ & \\
\hline No & $96(29.4)$ & $221(49.4)$ & \\
\hline \multicolumn{3}{|c|}{ Dispensed Antibiotic without Prescription } & 0.002 \\
\hline Yes & $171(52.5)$ & $285(63.8)$ & \\
\hline No & $155(47.5)$ & $162(36.2)$ & \\
\hline \multicolumn{3}{|c|}{ Under which demand level Antibiotic is dispensed } & 0.269 \\
\hline Demand Level 1 & $156(91.2)$ & $269(94.4)$ & \\
\hline Demand Level 2 & $15(8.8)$ & $16(5.6)$ & \\
\hline \multicolumn{3}{|c|}{ Did the Staff requested a prescription } & $<0.001$ \\
\hline Yes & $75(23)$ & $55(12.3)$ & \\
\hline No & $251(77)$ & $392(87.7)$ & \\
\hline \multicolumn{3}{|c|}{ Recommended a referral to physician } & $<0.001$ \\
\hline Yes & $91(27.9)$ & $65(14.5)$ & \\
\hline No & $235(72.1)$ & $382(85.5)$ & \\
\hline \multicolumn{3}{|c|}{ Provided counseling or advice about drugs dispensed } & 0.136 \\
\hline Yes & $140(42.9)$ & $167(37.4)$ & \\
\hline No & $186(57.1)$ & $280(62.6)$ & \\
\hline
\end{tabular}

\section{Discussion}

This study discloses the misuse and irrational dispensing of antibiotics in children from Lahore city of Punjab Province which was much higher for both acute diarrhea and acute URTI. The excessive antimicrobial dispensing at drugstores had also been reported in another province of Pakistan for acute diarrhea [31] and was also prevalent many years ago in few cities of Pakistan. [32, 33]. In 2017, Pakistan reacted immediately to address the issue of increased emergence of AMR and formulated a National Action Plan (NAP) following the proposals presented by WHO to promote the rational and appropriate use of antibiotics and to enforce their availability with a legal prescription. Despite the existence of strict legislation and a quick response to WHO's Global Action Plan on AMR, our study demonstrates that irrational dispensing practices have not yet been mitigated and retail stores are still an easy source of obtaining antibiotics unlawfully. Poor antimicrobial control at community levels, despite strict policies, was also observed in many studies conducted in Asian, African, and European countries [9-12, 34, 35].

During our survey, it was found that there was an absence of qualified pharmacists in a significantly high number of drugstores. This implies that either majority of the drugstores had not employed pharmacists or the licensed pharmacists were not on duty during the visits of simulated clients. Approximately, $79 \%$ of 
pharmacies were not supervised by a pharmacist. Another simulated study conducted in a South Asian country reported the absence of pharmacists at the drugstores [13]. On the contrary, in studies conducted in Saudi Arabia and a South European country (Belgium), there was an abundance of qualified pharmacists at drugstores [12],[36]. The presence of qualified pharmacists did not significantly affect the availability of antibiotics in a nationwide study conducted in China [37]. On the contrary, in another study in China, it was found that the presence of a pharmacist is significantly associated with a lower likelihood of dispensing antibiotics without a prescription [9]. Also, in Sri Lanka, a reduction in the dispensing of antibiotics was observed because of the presence of a pharmacist [13],[38]. In addition to an increased proportion of antibiotics dispensed due to the non-availability of pharmacists, our study also demonstrates that the unsupervised drugstores resulted in a significantly poor quality of health services in terms of inquiries about patient condition, medical history, and counseling practices. Most of the staff didn't even ask about the signs and symptoms of the children. It seemed that in any case, the choice of the antibiotic was already made after knowing the age of the child, irrespective of whether the presence of other symptoms.

Cefixime and ciprofloxacin were commonly dispensed for pediatric diarrhea and URTI. The frequent administration of a broad-spectrum antibiotic like cefixime alters the normal flora of the colon. Also, the third-generation cephalosporins and fluoroquinolones are associated with community-acquired clostridium difficle infections which have lethal consequences for children in terms of increased mortality, high costs, and longer stays in hospitals [39]. Thus, the usefulness of these antibiotics in pediatric acute infections has a big question mark because these antibiotic drugs may be hazardous for children's health. Ciprofloxacin was also commonly dispensed in some simulation studies conducted in China, Sri Lanka, and India [9],[13],[40]. The increased consumption of fluoroquinolones is also associated with the increased emergence of methicillin-resistant staphylococcus aureus (MRSA) [41]. Fluoroquinolones use in Pakistan has increased considerably over a few years and the Drug Registration Board has issued an advisory regarding the use of fluoroquinolones because of their tendency to cause serious side effects like tendon rupture, irreversible nerve damage, and peripheral neuropathy [42].

The considerably lower cost of the medications and their convenient over-the-counter access make them tend to be an appealing choice for caretakers. It was noticed that several of the antibiotics provided for the children in this study were self-prescribed by the drugstore staff. In our study, more than $93 \%$ of antibiotics were dispensed at the desire and advice of the drugstore staff (Demand Level 1), either because of their limited knowledge or business interests. This indicates that the motive of the drugstores to promote their businesses and/or the inappropriate clinical norms prevalent in the society are driving factors for increased inappropriate use of antibiotics at retail outlets besides customer expectations or therapeutic necessities. In some studies, antibiotics were dispensed at the recommendation of the drugstore staff [11],[40],[43]. Conversely, in many simulated studies, antibiotics were mostly sold or dispensed by customer demand rather on the advice and recommendation of the attending staff [9],[44], [45]. Prescriptions were requested from the SCs in only $16.8 \%$ cases which indicates that strict implementation of the drug rules is required at the drugstores. A campaign has been launched recently by the Primary and Secondary Healthcare Department of the Punjab, Province and official notification has 
been issued to monitor the sale of prescription based antibiotics at all retail outlets in the Punjab Province. The campaign is launched after increased AMR levels were observed in typhoid cases due to the extensive use of antibiotics [46]. However, the active participation of policymakers in the campaign will determine its fate.

Some limitations might be associated with our study. Firstly, there may have been some variations in the perceived characteristics of the drugstores and their staff by the simulated clients. An effort was made to minimize this disparity through comprehensive training and hands-on practical visits to some drugstores before starting the main study. Still, the dissimilarity cannot be completely overruled. Secondly, the SCs only presented the disease scenarios for children. So, the findings might not directly generate to dispensing practices for adults and elderly people. Finally, the study was carried out at the drugstores located in urban and suburban population, therefore, the practices in the rural population, which might be dissimilar, remained undisclosed.

\section{Conclusions}

The malpractice of dispensing non-prescription antibiotics is highly prevalent at drugstores of Lahore, Pakistan. Most of the antibiotics were not dispensed by qualified and well-trained staff and not according to standard disease management guidelines. This reflects the incorrect practices as well as a lack of awareness among the staff regarding the accurate use of antibiotics. For that reason, it is the right time to restrict the open-market availability of the prescription-only antibiotics by imposing high surveillance on the drugstores to avoid the hazardous effects of these medications. The strict implementation of prescription-only sales of antibiotics by Drug Regulatory Authority of Pakistan in the major cities such as capital cities of each province can be a useful first step to mitigate irrational use of antibiotics.

\section{Abbreviations}

AMR-Antimicrobial resistance, WHO- World Health Organization, SC- Simulated clients, URTI- Upper Respiratory Tract Infections, OTC- Over-the-counter, $\mathrm{Cl}$ - Confidence Interval, OR- Odds ratio

\section{Declarations}

\section{Ethics approval and consent to participate}

Ethical approval was obtained by the Biomedical Ethics Committee for Medical Research of Xi'an Jiaotong University (Approval number:2019-0161) and Ethics Committee of University College of Pharmacy, University of the Punjab, Lahore, Pakistan.

\section{Consent for publication}

Not Applicable. 
Availability of data and materials

The datasets used and/or analyzed during the current study are available from the corresponding author on reasonable request. All relevant data are included in this published article (and its supplementary files).

\section{Competing interests}

The authors declare that they have no competing interests.

\section{Funding}

This research was funded by "Young Talent Support Program” of Health Science Center, Xi'an Jiaotong University, Xi'an, China.

\section{Authors' contributions}

Conceptualization, (U.R.M and Y.F); methodology, (U.R.M, F.U.K and F.H); data analysis, (J.C, K.H and U.R.M); data entry (F.U.K, N.A and U.R.M); writing- original draft preparation, (U.R.M, K.L and H.B) writingreview and editing, (J.C, H.B, J.A.K and N.A); supervision, (Y.F); funding acquisition (Y.F). All authors have read and agreed to the published version of the manuscript.

\section{Acknowledgements}

We express gratitude and appreciation to the pharmacy students of University College of Pharmacy, University of The Punjab, Lahore, Pakistan who acted as simulated clients for the collection of data from the drugstores.

\section{Author details}

${ }^{1}$ Department of Pharmacy Administration and Clinical Pharmacy, School of Pharmacy, Xi'an Jiaotong University, Xi'an 710061, China.

${ }^{2}$ Center for Drug Safety and Policy Research, Xi'an Jiaotong University, Xi'an 710061, China.

${ }^{3}$ Research Institute for Drug Safety and Monitoring, Institute of Pharmaceutical Science and Technology, China's Western Technology Innovation Harbour, Xi'an 710000, China.

${ }^{4}$ University College of Pharmacy, University of the Punjab, Lahore 54000, Pakistan.

${ }^{5}$ Royal Albert Edward Infirmary, Wigan WN1 2NN, United Kingdom.

\section{References}


1. World Health Organization (WHO). Antibiotic Resistance: Multi-Country Public Awareness Survey [Internet]. 2015. http://apps.who.int/iris/bitstream/10665/194460/1/9789241509817_eng.pdf?ua=1

2. World Health Organization. Global Action Plan on Antimicrobial Resistance [Internet]. 2015. https://www.who.int/antimicrobial-resistance/publications/global-action-plan/en/

3. Marquet K, Liesenborgs A, Bergs J, Vleugels A, Claes N. Incidence and outcome of inappropriate inhospital empiric antibiotics for severe infection: A systematic review and meta-analysis. Crit Care. 2015;19(1). https://doi.org/10.1186/s13054-015-0795-y

4. Goossens H, Ferech M, Vander Stichele R, Elseviers M. Outpatient antibiotic use in Europe and association with resistance: a cross-national database study. Lancet. 2005;365(9459):579-87.

5. Shah JJ, Ahmad H, Rehan BB, Najeeb S, Mumtaz M, Jilani HH, et al. Self-medication with antibiotics among non-medical university students of Karachi: A cross-sectional study. BMC Pharmacol Toxicol. 2014;15(1):1-7.

6. World Health Organization (WHO). WHO Report on Surveillance of Antibiotic Consumption. 2018.

7. Van Boeckel TP, Gandra S, Ashok A, Caudron Q, Grenfell BT, Levin SA, et al. Global antibiotic consumption 2000 to 2010: An analysis of national pharmaceutical sales data. Lancet Infect Dis. 2014;14(8):742-50.

8. Morgan DJ, Okeke IN, Laxminarayan R, Perencevich EN, Weisenberg S. Non-prescription antimicrobial use worldwide: A systematic review. Lancet Infect Dis. 2011;11(9):692-701. http://dx.doi.org/10.1016/S1473-3099(11)70054-8

9. Chang J, Xu S, Zhu S, Li Z, Yu J, Zhang Y, et al. Assessment of non-prescription antibiotic dispensing at community pharmacies in China with simulated clients: a mixed cross-sectional and longitudinal study. Lancet Infect Dis. 2019;3099(19):1-10. http://dx.doi.org/10.1016/S1473-3099(19)30324-X

10. Horumpende PG, Sonda TB, van Zwetselaar M, Antony ML, Tenu FF, Mwanziva CE, et al. Prescription and non-prescription antibiotic dispensing practices in part I and part II pharmacies in Moshi Municipality, Kilimanjaro Region in Tanzania: A simulated clients approach. PLoS One. 2018;13(11):1-14.

11. Llor C, Cots JM. The Sale of Antibiotics without Prescription in Pharmacies in Catalonia, Spain. Clin Infect Dis. 2009;48(10):1345-9. https://doi.org/10.1086/598183

12. Driesen A, Vandenplas Y. How do pharmacists manage acute diarrhoea in an 8-month-old baby? A simulated client study. Int J Pharm Pract. 2009;17(4):215-20.

13. Zawahir S, Lekamwasam S, Aslani P. Antibiotic dispensing practice in Sri Lankan community pharmacies: A simulated client study. Res Soc Adm Pharm. 2019;15(5):584-90. https://doi.org/10.1016/j.sapharm.2018.07.019

14. Cars O, Nordberg P. Antibiotic resistance-The faceless threat. Int J Risk Saf Med. 2005;17:103-10.

15. Hadi MA, Karami NA, Al-Muwalid AS, Al-Otabi A, Al-Subahi E, Bamomen A, et al. Community pharmacists' knowledge, attitude, and practices towards dispensing antibiotics without prescription (DAwP): A cross-sectional survey in Makkah Province, Saudi Arabia. Int J Infect Dis. 2016;47:95100. https://doi.org/10.1016/j.jijid.2016.06.003 
16. Collignon P, Athukorala PC, Senanayake S, Khan F. Antimicrobial resistance: The major contribution of poor governance and corruption to this growing problem. PLoS One. 2015;10(3):1-13.

17. Cars O, Högberg L. Innovating for antibacterial resistance. ESCMID News. 2008;2(23):22-4.

18. Zaidi AKM, Huskins WC, Thaver D, Bhutta ZA, Abbas Z, Goldmann DA. Hospital-acquired neonatal infections in developing countries. Lancet. 2005;365(9465):1175-88.

19. Gerber JS, Newland JG, Hospital M, City K, Coffin SE, Hall M, et al. Variability in Antibiotic Use at Children's Hospitals Throughout the United States. Pediatrics. 2010;126(6):1067-73.

20. van Houten CB, Cohen A, Engelhard D, Hays JP, Karlsson R, Moore E, et al. Antibiotic misuse in respiratory tract infections in children and adults- a prospective, multicentre study (TAILORED Treatment). Eur J Clin Microbiol Infect Dis. 2019;38(3):505-14.

21. Hersh AL, Shapiro DJ, Pavia AT, Shah SS. Antibiotic prescribing in ambulatory pediatrics in the United States. Pediatrics. 2011;128(6):1053-61.

22. World Bank. The Under-5 Mortality Rate in Pakistan in 2018 [Internet]. [Accessed 2020 Aug 19]. https://data.worldbank.org/indicator/SH.DYN.MORT? contextual=region\&end=2018\&locations $=P K \&$ start $=1960$

23. Ministry of National Health Services Regulations \& Coordination G of P. Antimicrobial Resistance: National Action Plan Pakistan [Internet]. 2017. https://www.nih.org.pk/amr-national-action-planpakistan/

24. Saleem Z, Hassali MA, Hashmi FK, Godman B, Saleem F. Antimicrobial dispensing practices and determinants of antimicrobial resistance: A qualitative study among community pharmacists in Pakistan. Fam Med Community Heal. 2019;7(3).

25. Hussain A, Ibrahim MIM. Qualification, knowledge and experience of dispensers working at community pharmacies in Pakistan. Pharm Pract. 2011;9(2):93-100.

26. Butt ZA, Gilani AH, Nanan D, Sheikh AL, White F. Quality of pharmacies in Pakistan: A cross-sectional survey. Int J Qual Heal Care. 2005;17(4):307-13.

27. Gillani AH, Ji W, Imran A, Chang J. Antibiotic Self-Medication among Non-Medical University Students in Punjab, Pakistan: A Cross-Sectional Survey. 2017;(October).

28. Gastelurrutia MA, Larrañaga B, Garay A, Echeveste FA, Fernandez-Llimos F. Impact of a program to reduce the dispensing of antibiotics without a prescription in Spain. Pharm Pract (Granada). 2013;11(4):185-90.

29. Administrative Towns of Lahore [Internet]. [Accessed 2020 Jun 24]. https://lgcd.punjab.gov.pk/tma_lahore

30. Raosoft Sample Size Calculator [Internet]. http://www.raosoft.com/samplesize.html

31. Khan A, Iqbal Q, Haider S, Khalid A, Hassali MA, Saleem F. Acute Diarrheal Management in Adults: A Simulated Client Study at Community Pharmacies of Quetta City, Pakistan. J Pharm Pract Community Med. 2019;5(1):13-7. 
32. Hussain A, Ibrahim MIM. Management of diarrhoea cases by community pharmacies in 3 cities of Pakistan. East Mediterr Heal J. 2012;18(6):635-40. https://doi.org/10.26719/2012.18.6.635

33. Hussain A, Ibrahim MIM, Malik M. Assessment of disease management of acute respiratory tract infection at community pharmacies through simulated visits in Pakistan. Lat Am J Pharm. 2012;31(10):1435-40.

34. Ekwochi U, Chinawa JM, Obi I, Obu HA, Agwu S. Use and/or misuse of antibiotics in management of diarrhea among children in Enugu, Southeast Nigeria. J Trop Pediatr. 2013;59(4):314-6.

35. Vogler S, Vitry A, Ud-Bin-Babar Z. Prices of oncology medicines in European countries, Australia and New Zealand. J Pharm Policy Pract. 2015;8(Suppl 1):P16. http://www.joppp.org/content/8/S1/P16

36. Al-Mohamadi A, Badr A, Bin Mahfouz L, Samargandi D, Al Ahdal A. Dispensing medications without prescription at Saudi community pharmacy: Extent and perception. Saudi Pharm J. 2013;21(1):13-8. http://dx.doi.org/10.1016/j.jsps.2011.11.003

37. Chen J, Wang YM, Jie CX, Hesketh T. Ease of access to antibiotics without prescription in Chinese pharmacies: a nationwide cross-sectional study. Lancet. 2018;392:80.

38. Zawahir S, Lekamwasam S, Aslani P. Community pharmacy staff's response to symptoms of common infections: a pseudo-patient study. Antimicrob Resist Infect Control. 2019;8(1):1-10.

39. Adams DJ, Eberly MD, Rajnik M, Nylund CM. Risk Factors for Community-Associated Clostridium difficile Infection in Children. J Pediatr. 2017;186:105-9.

http://dx.doi.org/10.1016/j.jpeds.2017.03.032

40. Shet A, Sundaresan S, Forsberg BC. Pharmacy-based dispensing of antimicrobial agents without prescription in India: Appropriateness and cost burden in the private sector. Antimicrob Resist Infect Control. 2015;4(1):1-7. http://dx.doi.org/10.1186/s13756-015-0098-8

41. Parienti JJ, Cattoir V, Thibon P, Lebouvier G, Verdon R, Daubin C, et al. Hospital-wide modification of fluoroquinolone policy and meticillin-resistant Staphylococcus aureus rates: A 10-year interrupted time-series analysis. J Hosp Infect. 2011;78(2):118-22. http://dx.doi.org/10.1016/j.jhin.2011.03.008

42. Center for Disease Dynamics E and P (CDDEP). Situation Analysis Report on Antimicrobial Resistance in Pakistan- Findings and Recommendations for Antibiotics use and resistance. 2017.

43. Bin Abdulhak AA, Altannir MA, Almansor MA, Almohaya MS, Onazi AS, Marei MA, et al. Non prescribed sale of antibiotics in Riyadh, Saudi Arabia: A cross sectional study. BMC Public Health. 2011;11:1-5.

44. Chang J, Ye D, Lv B, Jiang M, Zhu S, Yan K, et al. Sale of antibiotics without a prescription at community pharmacies in urban China: A multicentre cross-sectional survey. J Antimicrob Chemother. 2017;72(4):1235-42. https://doi.org/10.1093/jac/dkw519

45. Shi L, Chang J, Liu X, Zhai P, Hu S, Li P, et al. Dispensing antibiotics without a prescription for acute cough associated with common cold at Community Pharmacies in Shenyang, Northeastern China: A cross-sectional study. Antibiotics. 2020;9(4):1-16.

46. Primary and Secondary Healthcare Deartment $G$ of P. Monitoring of prescription based sale of Schedule B and Schedule D drugs [Internet]. [Accessed 2020 Aug 14]. https://pshealthpunjab.gov.pk/ 


\section{Supplementary Files}

This is a list of supplementary files associated with this preprint. Click to download.

- AdditionalFile1.docx

- AdditionalFile1.docx 